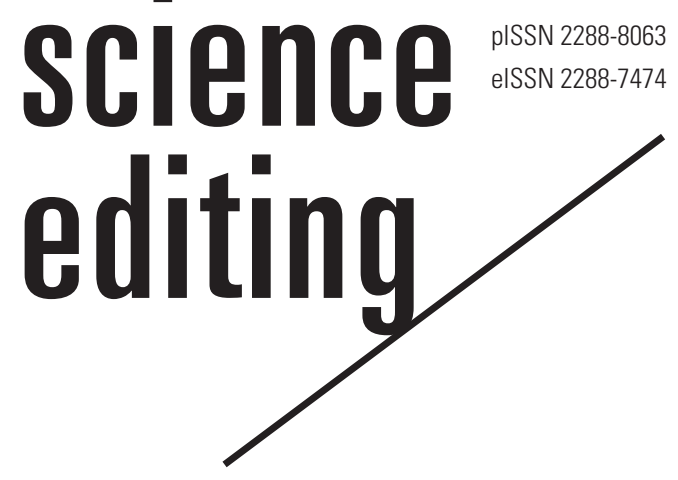

\title{
Bibliographic and content analysis of physics papers from North Korea indexed in the Scopus from 2005 to 2018
}

\author{
Kihong Kim ${ }^{1,2}$, Yeonok Chung ${ }^{3}$ \\ 'Department of Energy Systems Research and Department of Physics, Ajou University, Suwon; ${ }^{2}$ School of Physics, Korea \\ Institute for Advanced Study, Seoul; ${ }^{3}$ Department of Social Welfare, Jangan University, Hwaseong, Korea
}

Abstract

Purpose: It aimed at assessing the current status of physics research in North Korea through a bibliographic and content analysis of the physics papers from North Korea indexed in the Scopus from 2005 to 2018.

Methods: The Scopus was searched on January 18, 2019 by using the search option 'Affiliation city' with "Pyongyang OR Chongjin OR Hamhung OR Sariwon OR Wonsan OR Kimchaek" as the city name and 171 physics papers from North Korea written in English were identified. By performing supplementary searches based on the author names and the references, $46 \mathrm{pa}$ pers belonging to physics were added and the total of 217 papers were identified. They were classified by publication year, co-authors' country, institution, subfield, journal and author. Representative North Korean physicists and the active subfields of physics were identified.

Results: The number of physics papers from North Korea has been growing rapidly in the recent years. Physics research activities in North Korea were extremely centralized in its capital, Pyongyang, where all major research institutions were located. Major research areas included condensed matter physics, optics and high energy physics and the large majority of papers were theoretical ones. From a bibliographic and content analysis, sixteen representative or notable physicists in North Korea were identified.

Conclusion: It appears that the North Korean government is actively encouraging researchers to publish more papers in international journals. There is a strong growth potential in physics research in North Korea. In order to achieve balanced development in physics, it is an impor-

Received: February 11, 2019 Accepted: February 12, 2019

Correspondence to Kihong Kim khkim@ajou.ac.kr

ORCID

Kihong Kim

https://orcid.org/0000-0001-9965-3535 Yeonok Chung

https://orcid.org/0000-0003-0008-5772 tant task to build competitive experimental groups.

Keywords

Bibliography; North Korea; Physics research
This is an open access article distributed under the terms of the Creative Commons Attribution License (http://creativecommons.org/licenses/by/4.0/), which permits unrestricted use, distribution, and reproduction in any medium, provided the original work is properly cited. 


\section{Introduction}

North Korea is perhaps the most closed society in the current world. It has had little interaction with a large part of the outside world in many areas of human activities. This is also the case with academic activities, as we can see from the very small number of papers from North Korea published in international journals. Recently, Jeong and Huh performed the first extensive bibliometric analysis of North Korean publications in all academic disciplines indexed in the Web of Science Core Collection during the last forty years $[1,2]$. They also performed a bibliometric and content analysis of medical articles in the PubMed database published by North Korean authors during the last twenty years [3]. One of the findings from this study is that even though the total number of publications from North Korea is extremely small compared to more developed countries, it has been increasing fairly rapidly in recent years. In this article, we extend this line of study and perform a detailed bibliographic and content analysis of North Korean publications in the discipline of physics published during the last fourteen years, based on the search results of the Scopus database. We find the yearly variation of the number of papers and examine which foreign countries North Korean physicists have collaborated with. We identify major research institutions and the journals where multiple papers were published. We also classify the number of papers by various subfields of physics. Finally, we identify some representative North Korean physicists who have produced a substantial number of high-quality papers. In the Discussion, we comment on the current status and future prospect of physics research in North Korea.

\section{Methods}

We performed the search of the Scopus database on January 18, 2019. Initially, we used the Scopus search option 'Affiliation country' with "North Korea" as the country name. We found that this search yielded rather inaccurate results because many papers with South Korean affiliations were wrongly included. We also found that there were many reverse cases where North Korean institutions were searched as South Korean. By manually going through the affiliations of North Korean authors, we found that in almost all cases, the city where the institutions were located was Pyongyang, the capital city of North Korea. Through an extensive survey of the affiliations and additional searches, we found that except for Pyongyang, only five other North Korean cities, which were Chongjin, Hamhung, Sariwon, Wonsan and Kimchaek, appeared in the addresses of North Korean papers. Therefore, we used the Scopus search option 'Affiliation city' with
"Pyongyang OR Chongjin OR Hamhung OR Sariwon OR Wonsan OR Kimchaek" as the city name. We have found that this way of searching for North Korean papers is the most accurate method. Using this method, we found that before 2005, there were only a very small number of papers from North Korea. From 2005 to 2018, we found 791 North Korean papers in all academic disciplines, 190 of which were classified as belonging to the subject area of physics and astronomy according to the Scopus. Among these, 171 papers were in English and 19 were in Chinese.

We restricted our study only to the papers written in English. Through a careful survey of the references of the 171 English-language papers found above, we realized that there were a substantial number of missing papers and the classification by the subject area in the Scopus database was not sufficiently accurate. To correct this deficiency, we performed supplementary searches based on the author names in addition to finding missing physics papers manually from the references. With this procedure, we found 46 additional papers from North Korea, which clearly belonged to physics but were not included in our original search results. By adding these, we obtained our basic set of 217 papers.

Next, we conducted a detailed survey of the bibliographic data, such as authors, institutions, countries and journals and examined the content of each paper to determine which subfield of physics it belonged to and whether it was primarily theoretical or experimental. We classified the papers by publication year, co-authors' country, institution, subfield, journal and author. From this study, we identified some representative North Korean physicists and the subfields of physics in which active research was performed in North Korea.

\section{Results}

In order to make a quantitative comparison between the number of publications from North Korea and that from South Korea, we first consider the search results obtained without the supplementary searches described in the Methods section. The number of North Korean papers in all fields published from 2005 to 2018 was 791 . We compare this with the number of South Korean papers during the same period, which was 922,677 . This number was obtained using the search option 'Affiliation country' with "Korea" as the country name and then subtracting 791 from the obtained result. We find that the number of papers from North Korea is merely $0.086 \%$ of that from South Korea as shown in Table 1. The ratio of the physics and astronomy papers from North Korea and those from South Korea during the same period is slightly higher and is equal to $0.121 \%$. In order to find a more recent trend, we also calculated similar ratios for the papers 
Table 1. Comparison between the numbers of all papers from South Korea and those from North Korea published during the period of 2005 to 2018 and during the period of 2016 to 2018

\begin{tabular}{|c|c|c|c|c|c|c|}
\hline Period & $\begin{array}{l}\text { No. of all papers } \\
\text { from South Korea }(A)\end{array}$ & $\begin{array}{l}\text { No. of all papers } \\
\text { from North Korea (B) }\end{array}$ & $100 \mathrm{~B} / \mathrm{A}(\%)$ & $\begin{array}{l}\text { No. of physics and } \\
\text { astronomy papers } \\
\text { from South Korea (C) }\end{array}$ & $\begin{array}{l}\text { No. of physics and } \\
\text { astronomy papers } \\
\text { from North Korea (D) }\end{array}$ & $100 \mathrm{D} / \mathrm{C}(\%)$ \\
\hline 2005-2018 & 922,677 & 791 & 0.086 & 157,617 & 190 & 0.121 \\
\hline 2016-2018 & 251,262 & 368 & 0.146 & 36,475 & 98 & 0.269 \\
\hline
\end{tabular}

Similar comparisons are made also for physics and astronomy papers.

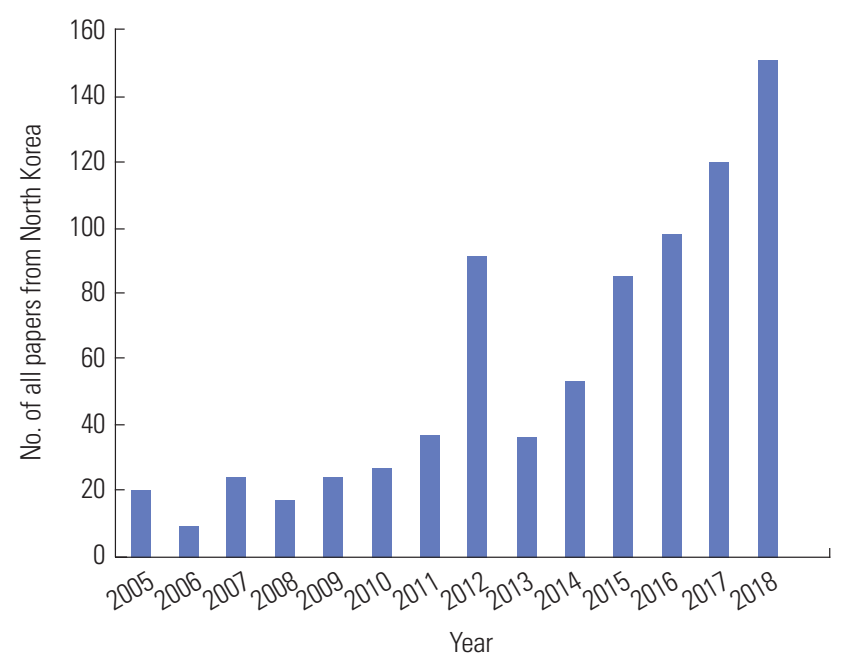

Fig. 1. Yearly variation of all papers from North Korea.

published during the recent three years from 2016 to 2018 . We find that the ratio for all papers and that for physics and astronomy papers have increased to $0.146 \%$ and $0.269 \%$ respectively. In Fig. 1 (Suppl. 1), we show the yearly variation of all papers from North Korea published from 2005 to 2018. We observe that the number has been increasing rapidly in recent years.

As we have explained in the Methods section, the classification of papers by subject area in the Scopus database is not very accurate. For example, we found 10 papers from North Korea published in the journal Plasmonics, which should clearly be classified as physics papers but were not included in the original search result. By performing the supplementary searches described in the Methods section, we corrected this deficiency and obtained the main set of 217 papers in the discipline of physics and astronomy, which we plotted in Fig. 2 by year (Suppl. 2). Only one of them was in the field of astronomy. We also identified the papers written by only North Korean authors and plotted them by year in Fig. 2. The total number of these all-North Korean papers with no international collaboration, which appeared only after 2012, was 79, which was about $36.4 \%$ of the total. We observe that both numbers have been increasing quite rapidly in the recent few

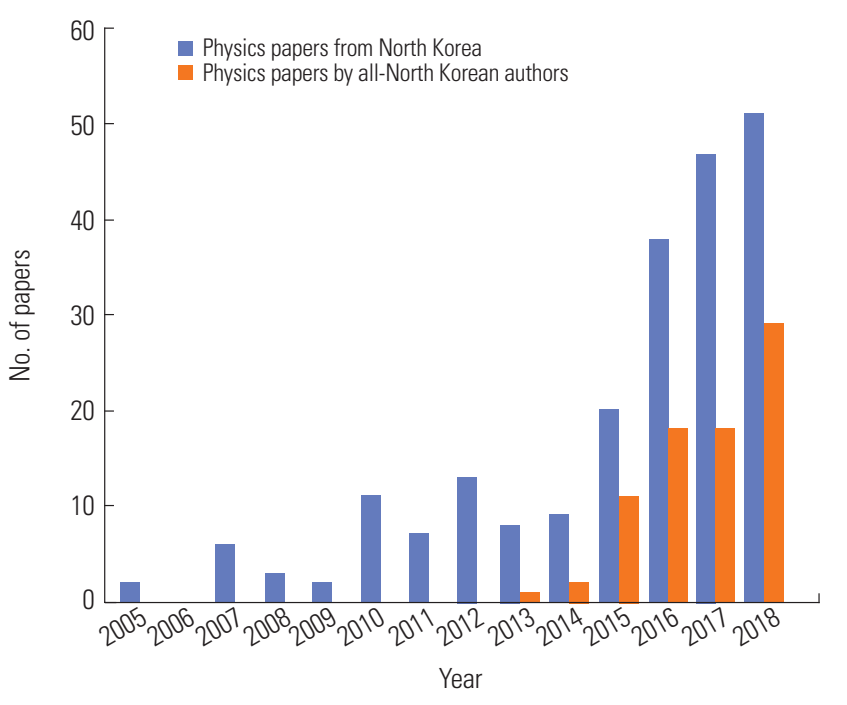

Fig. 2. Yearly variations of the number of all physics papers from North Korea and that of physics papers written by all-North Korean authors. The total number of all physics papers shown here, 217, is larger than the corresponding number in Table 1, 190, because we added the number of physics papers found by the supplementary searches described in the Methods section.

years. We found that nine physics papers from North Korea appeared already during the first half-month of 2019, though we did not include the data in this article. Using this number, we project that in 2019, over 100 physics papers from North Korea can appear in the Scopus. From such a rapid increase in the number of publications, we suspect that the North Korean government has an active policy to encourage researchers to publish more papers in international journals.

The majority of the 217 papers from North Korea were written in collaboration with other countries. In Table 2, we list the top five foreign countries to which the largest number of physics papers from North Korea are affiliated. Seventy-nine papers constituting $36.4 \%$ of the total were written by only North Korean authors and the rest 138 papers $(63.6 \%)$ were written in collaboration with other countries. We find that China and Germany are the main partner countries of North Korea. China accounts for $37.8 \%$ and Germany accounts for $23 \%$ of the total papers respectively. 
Table 2. Top five foreign countries to which the largest number of physics papers with North Korean authors are affiliated

\begin{tabular}{lcc}
\hline Co-authors' country & No. of papers & Percentage in the total \\
\hline China & 82 & 37.8 \\
Germany & 50 & 23.0 \\
Italy & 4 & 1.8 \\
USA & 4 & 1.8 \\
Russia & 3 & 1.4 \\
None (all-North Korean authors) & 79 & 36.4
\end{tabular}

The numbers are compared with that of physics papers written by all-North Korean authors.

Table 3. Top seven institutions to which the largest number of physics papers are affiliated

\begin{tabular}{lcc}
\hline Institution & $\begin{array}{c}\text { No. of } \\
\text { papers }\end{array}$ & $\begin{array}{c}\text { Percentage in } \\
\text { the total }\end{array}$ \\
\hline Kim II Sung University & 131 & 60.4 \\
University of Science & 25 & 11.5 \\
Institute of Lasers & 25 & 11.5 \\
Kimchaek University of Technology & 22 & 10.1 \\
Institute of Physics & 8 & 3.7 \\
Kim Hyong Jik Normal University & 7 & 3.2 \\
Institute of Mathematics & 6 & 2.8 \\
\hline
\end{tabular}

In addition, we counted the number of papers where a North Korean author is either the first author or the corresponding author. We found that in 172 papers, which were 79.3\% of the total, a North Korean was the first author. In the cases where we can identify the corresponding author from the bibliographic data, we found that a North Korean was the corresponding author in 111 papers, which was about 51.2\% of the total. We conclude that North Korean researchers have played a major role in the large majority of papers.

Physics research activities in North Korea seem to be extremely centralized in Pyongyang, the North Korean capital. In fact, 215 papers out of the total 217 are affiliated to Pyongyang. Chongjin and Hamhung appear respectively in two papers and Kimchaek appears in one paper. The sum of these numbers is greater than 217 due to some papers affiliated to multiple cities. Four institutions, which include Kim Il Sung University, University of Science, Kimchaek University of Technology and the Institute of Lasers, are responsible for about $90 \%$ of the total publications. Among these, Kim Il Sung University, which takes $60.4 \%$, is the single most dominant institution. All of the top seven institutions with the largest number of papers listed in Table 3 are located in Pyongyang.
Table 4. Classification of the number of papers by various subfields of physics

\begin{tabular}{lccc}
\hline Field & $\begin{array}{c}\text { No. of } \\
\text { theoretical } \\
\text { papers }\end{array}$ & $\begin{array}{c}\text { No. of } \\
\text { experimental } \\
\text { papers }\end{array}$ & Total no. \\
\hline Optics, photonics & 51 & 6 & 57 \\
$\begin{array}{l}\text { Condensed matter physics, } \\
\text { materials physics }\end{array}$ & 45 & 10 & 55 \\
Applied physics, engineering physics & 14 & 6 & 20 \\
High energy physics, string theory, & 18 & 0 & 18 \\
$\quad$ cosmology & 12 & 2 & 14 \\
Nonlinear physics & 10 & 3 & 13 \\
Chemical physics & 12 & 0 & 12 \\
Soft matter physics & 0 & 8 & 8 \\
Biological physics & 7 & 0 & 7 \\
Mathematical physics & 1 & 3 & 4 \\
Nuclear physics & 3 & 0 & 3 \\
Plasma physics & 2 & 0 & 2 \\
Fluid physics & 2 & 0 & 2 \\
Quantum information & 1 & 0 & 1 \\
Statistical physics & 1 & 0 & 1 \\
Astronomy & & 38 & 217 \\
Total & 19 & & \\
\hline
\end{tabular}

Table 5. List of all journals where more than two North Korean physics papers were published

\begin{tabular}{lc}
\hline Journal & No. of papers \\
\hline Optics Express & 12 \\
Journal of High Energy Physics & 11 \\
Plasmonics & 10 \\
Physica B & 8 \\
Physical Review E & 7 \\
Physical Chemistry Chemical Physics & 5 \\
Journal of Materials Science & 5 \\
Physical Review B & 4 \\
Laser Physics & 4 \\
Chemical Physics Letters & 4 \\
Journal of Electronic Materials & 4 \\
Radiation Effects and Defects in Solids & 4 \\
Proceedings of SPIE & 4 \\
Physical Review A & 3 \\
Applied Physics A & 3 \\
Applied Physics B & 3 \\
Scientific Research & 3 \\
Journal of Power Sources & 3 \\
Electrochimica Acta & 3 \\
\hline
\end{tabular}


We next examined the contents of the 217 papers and classified them by various subfields of physics. Nowadays, it is difficult to make such a classification unambiguously and accurately because many research topics are interdisciplinary and therefore many papers belong to several research areas simultaneously. Nevertheless, we attempted the classification and listed the result in Table 4. The top two fields where the largest numbers of papers were published were optics/photonics and condensed matter physics/materials physics. Other areas of research where many papers were published included applied physics/engineering physics, high energy physics/ string theory/cosmology, nonlinear physics, chemical physics, soft matter physics and biological physics. Curiously, we notice that there were only four papers in the field of nuclear physics, though we expect the level of nuclear physics research in North Korea will be quite high.

In modern physics, physicists usually choose to specialize in theoretical research or in experimental research. Since physics is based on the study of natural phenomena, the experimental research has always been considered as highly important and the number of experimental papers is substantially larger than that of purely theoretical papers in the usual case. An interesting and unusual aspect regarding the data in Table 4 is that in North Korea, the number of theoretical papers is much greater than that of experimental ones. The percentage of theoretical papers is $82.5 \%$ of the total. We suspect that in North Korea, there is a severe lack of modern hightechnology experimental equipment, which are essential in experimental research these days.

Next, we classify the papers by the journals where they are published. In Table 5, we list all journals where more than two North Korean physics papers were published. The top five journals are Optics Express, Journal of High Energy Physics, Plasmonics, Physica B and Physical Review E. In addition, there were 11 publications in American Physical Society (APS) journals other than Physical Review E, including Physi-

Table 6. Top six North Korean physicists with the largest number of papers

\begin{tabular}{|c|c|c|c|c|c|}
\hline Researcher & Institution & Major field & $\begin{array}{l}\text { Theory/ } \\
\text { experiment }\end{array}$ & $\begin{array}{l}\text { No. of } \\
\text { papers }\end{array}$ & Journals where multiple papers were published \\
\hline Chol-Jun Yu & Kim II Sung University & Materials physics & Theory & 24 & $\begin{array}{l}\text { Journal of Materials Science (5), Journal of Power Sources (3), Physical } \\
\text { Review B (2), Physical Review Applied (2), Physical Chemistry Chemical } \\
\text { Physics (2), Journal of Materials Chemistry A (2) }\end{array}$ \\
\hline Kwang-Hyon Kim & Institute of Lasers & Optics, photonics & Theory & 20 & Optics Express (7), Plasmonics (3), Annalen der Physik (2) \\
\hline Jin U Kang & Kim II Sung University & $\begin{array}{l}\text { High energy } \\
\text { physics, string } \\
\text { theory, cosmology }\end{array}$ & Theory & 15 & $\begin{array}{l}\text { Journal of High Energy Physics (9), Journal of Cosmology and } \\
\text { Astroparticle Physics (2) }\end{array}$ \\
\hline Nam-Chol Kim & Kim II Sung University & Optics, photonics & Theory & 15 & Plasmonics (6), Optics Express (3), Nanotechnology (2) \\
\hline Chol-Ung Choe & University of Science & Nonlinear physics & Theory & 13 & Physical Review E (7), International Journal of Dynamics and Control (2) \\
\hline
\end{tabular}

Table 7. List of some notable North Korean physicists other than those in Table 6

\begin{tabular}{llll}
\hline Researcher & \multicolumn{1}{c}{ Institution } & \multicolumn{1}{c}{ Major field } & Theory/experiment \\
\hline Jun-Sik Sin & Kim II Sung University & Soft matter physics & Theory \\
Chun-Sik Choe & Kim II Sung University & Biological physics & Optics, photonics \\
Yong-Hyok Kwon & Institute of Lasers & Condensed matter physics & Experiment \\
Hyok-Su Ryo & Kim II Sung University & Condensed matter physics, many body theory & Theory \\
Ha Kim & University of Science & Materials physics & Theory \\
Gum-Chol Ri & Kim II Sung University & Materials physics & Theory \\
Un-Gi Jong & Kim II Sung University & Optics, photonics & Theory \\
Myong-Chol Ko & Kim II Sung University & High energy physics, string theory, cosmology & Theory \\
Ok Song An & Kim II Sung University & Quantum information & Theory \\
Kwang-II Kim & Kim II Sung University & & Theory \\
\hline
\end{tabular}


cal Review A, Physical Review B, Physical Review D and Physical Review Applied. The majority of journals including the APS journals, Optics Express and Journal of High Energy Physics are considered high-quality journals in the physics community. Overall, we find that the large majority of North Korean physics papers appeared in relatively high-quality journals. One interesting comment we want to add is that among the 12 papers published in Optics Express, which is an open access journal with expensive publication charges, only one paper has a North Korean as the corresponding author.

Finally, we attempted to identify representative North Korean physicists who produced many high-quality research papers. In fact, we found that all of the top six researchers who published the largest number of papers in all academic disciplines were physicists. In Table 6, we list those six researchers, all of whom are theoretical physicists. It is interesting that the three of them are in the field of optics and photonics. Four researchers are from Kim Il Sung University. The other two are from the Institute of Lasers and University of Science respectively.

In Table 7, we list some notable North Korean physicists other than those in Table 6 . We selected researchers with a large number of publications or those majoring in timely research fields such as quantum information. We have to caution that our way of identifying productive researchers based only on the bibliographic information is rather limited and can be incomplete. We suspect that the majority of those in Table 7 are rather young. It appears that senior researchers who studied previously in Germany or in China returned to North Korea and have been building research groups actively.

Our final comment is concerned about the fraction of female physicists in North Korea. It is possible to guess the gender of a Korean based on the first name, though it is far from being an accurate method of determining gender. Among the names of all North Korean authors of the 217 papers, we found only one name which we could guess as a woman's name. From this, we guess that there are an extremely small percentage of women in the North Korean physics community.

\section{Discussion}

In this article, we have performed a detailed bibliographic and content analysis of the physics papers from North Korea indexed in the Scopus from 2005 to 2018. Even though the total number of publications from North Korea is extremely small compared to more developed countries, we have found that the number of papers has been growing quite rapidly in the recent few years. We think North Korea has a strong growth potential in the future in physics research, especially in theoretical physics research. Physics research activities in North Korea are extremely centralized in its capital city, Pyongyang, where all major research institutions are located. Major research areas include condensed matter physics, optics and high energy physics and the large majority of the papers are theoretical ones. In order to achieve balanced development in physics, it is essential to build strong experimental groups which are bigger than theoretical groups. This will be an important future task in North Korea. From a bibliographic and content analysis, we have identified sixteen representative or notable physicists in North Korea.

\section{Conflict of Interest}

Kihong Kim is the editor-in-chief of Science Editing; however, he was not involved in the peer reviewer selection, evaluation, or decision process of this article. No other potential conflicts of interest relevant to this article were reported.

\section{Supplementary Material}

The supplementary file is available from the Harvard Dataverse at: https://doi.org/10.7910/DVN/PQSDMG

Suppl. 1. Yearly variation of all papers from North Korea

Suppl. 2. Yearly variations of the number of all physics papers from North Korea and that of physics papers written by all-North Korean authors

\section{References}

1. Jeong GH, Huh S. Bibliometric analysis of publications from North Korea indexed in the Web of Science Core Collection from 1988 to 2016. Sci Ed 2017;4:24-9. https:// doi.org/ $10.6087 / \mathrm{kcse} .85$

2. Jeong GH, Huh S. Update: Bibliometric analysis of publications from North Korea indexed in the Web of Science Core Collection from 1978 to July 2018. Sci Ed 2018;5: 119-23. https://doi.org/10.6087/kcse.135

3. Jeong GH, Huh S. Bibliometric and content analysis of medical articles in the PubMed database published by North Korean authors from 1997 to July 2017. Sci Ed 2017;4:70-5. https://doi.org/10.6087/kcse.98 